\title{
Stable multi-infection of splenocytes during SIV infection - the basis for continuous recombination
}

\author{
Anke Schultz ${ }^{1}$, Sieghart Sopper ${ }^{2}$, Ulrike Sauermann ${ }^{3}$, Andreas Meyerhans $^{1,4}$ and Rodolphe Suspène ${ }^{1 *}$
}

\begin{abstract}
Background: Recombination is an important mechanism in the generation of genetic diversity of the human (HIV) and simian (SIV) immunodeficiency viruses. It requires the co-packaging of divergent RNA genomes into the same retroviral capsid and subsequent template switching during the reverse transcription reaction. By HIV-specific fluorescence in situ hybridization (FISH), we have previously shown that the splenocytes from 2 chronically infected patients with Castelman's disease were multi-infected and thus fulfill the in vivo requirements to generate genetic diversity by recombination. In order to analyze when multi-infection first occurs during a lentivirus infection and how the distribution of multi-infection evolves during the disease course, we now determined the SIV copy numbers from splenocytes of $11 \mathrm{SIVmac} 251$-infected rhesus macaques cross-sectionally covering the time span of primary infection throughout to end-stage immunodeficiency.
\end{abstract}

Results: SIV multi-infection of single splenocytes was readily detected in all monkeys and all stages of the infection. Single-infected cells were more frequent than double- or triple- infected cells. There was no strong trend linking the copy number distribution to plasma viral load, disease stage, or CD4 cell counts.

Conclusions: SIV multi-infection of single cells is already established during the primary infection phase thus enabling recombination to affect viral evolution in vivo throughout the disease course.

Keywords: SIV, FISH, Recombination, Provirus copy number

\section{Background}

The human (HIV) and simian (SIV) immunodeficiency viruses exhibit phenomenal genetic diversity. This diversity is generated by 3 different mechanisms, (i) errorprone replication by the reverse transcriptase that occurs without proofreading [1], (ii) hypermutation by host mutators of the family of cytidine deaminases [2-6] and (iii) recombination between the viral RNA genomes by template switching [7]. As a result of these processes, a population of virus variants or quasispecies is established within an infected host that is subsequently shaped by processes like fitness competition between variants, immune-mediated activation of infected cells and bottlenecking [8-11].

\footnotetext{
* Correspondence: rodolphe.suspene@pasteur.fr

'Department of Virology, Saarland University, Homburg D-66421, Germany Full list of author information is available at the end of the article
}

Due to the structure of the retrovirus particle and the low processivity of the reverse transcriptase, recombination is extraordinary frequent in HIV and SIV [12]. In fact, the number of crossovers during reverse transcription between the two RNA templates that are packaged within one HIV virion has been estimated to be around three or higher per genome [13-16]. Thus any generated single provirus can be expected to have a mosaic structure derived from its two parental viral RNA strands. In comparison, the point mutation rate with approximately 0.25 mutations per genome and replication [17] is at least a factor of 10 lower.

To have an impact on virus evolution, recombination needs to proceed between non-identical RNA strands. The requirements and biological steps for the generation of such virus particles with non-identical genomes have been described. First, multi-infection of single cells occurs via direct and via cell-mediated entry pathways
C Biomed Central 
[18]. Second, the existence of multi-infected cells has been directly shown by HIV-specific fluorescence in situ hybridization (FISH) on splenocytes of infected patients [19]. Third, transcribed HIV RNA genomes are co-packaged into virions at ratios expected from a random distribution [20]. However, the extent of sequence similarity, especially of the dimerization initiation site, influences co-packaging efficiency and consequently the frequency of observable recombinants [21-23].

While features of the basic steps in the generation of HIV/SIV recombinants have been described in various experimental conditions, it is still unknown when multiinfected single cells first appear in vivo during a lentivirus infection and how the distribution of multi-infection evolves during the disease course. To answer these questions, we determined the SIV copy number in splenocytes from SIVmac251-infected rhesus macaques (Macaca mulatta) by specific fluorescence in situ hybridization.

\section{Results and discussion}

Multi-infection of single splenocytes of SIV-infected rhesus macaques in all stages of infection

To determine the SIV copy number of splenocytes from SIVmac251-infected animals by FISH, DNA from SIVmac239 was used as a probe. This was possible due to the high sequence homology between SIVmac239 and SIVmac251 [24]. In vitro SIVmac239-infected CEMx174 cells served as positive control to test the sensitivity of the biotin-labelled SIV DNA-probe while un-infected CEMx174 cells as well as spleen cells from an un-infected rhesus macaque were used as negative controls. Only after detecting bright signals in the interphase nuclei of the infected CEMx174 cells with no nonspecific background in the negative samples, the splenocytes of the infected animals were analyzed under the same conditions.

Multi-SIV-infected cells were observed for all animals and throughout the entire observation period from primary infection (2 weeks post infection) to the AIDS state (animals 1740, 1778 and 1718; Figure 1 and Table 1). The relative distribution of provirus copy numbers was similar from the acute to the late stage of infection. With the exception of monkey 1778, cells with 1 provirus copy were more frequent than cells with 2 or 3 copies. Three provirus copies/cell were detected in 2 monkeys at 2 weeks and 51 weeks post infection, respectively. Thus multi-infection of single splenocytes is a general phenomenon that occurs during all stages of an SIV infection.

To evaluate the efficiency of the FISH assay and the error in our provirus copy number estimates, the technique has to be tested on cells with a defined copy number. For this we used U1 cells that carry 2 HIV provirus copies per genome and performed the assay under identical conditions only using HIV DNA as a probe. This is a valid approach as the base composition and thus the hybridization properties for HIV-1 and SIV are basically identical (HIV-1: A-35,3\%, T-22,1\%, G-24,4\%, C-18,2\% and SIV239: A-33,6\%, T-22,7\%, G-24,7\%, C-18,8\%). Approximately $10 \%$ of U1 cells showed only one copy. Thus it would appear that we underestimated the real values by $\sim 10 \%$. Within the same experiments, we very rarely detected 3 proviruses ( $<0.5 \%$ of cells). Likewise, using either HIV DNA or SIV DNA as probes, noninfected monkey splenocytes rarely gave a positive signal $(<0.5 \%)$ suggesting that the number of false positive events is very small. Extrapolating these findings to the SIV FISH experiments with splenocytes from infected monkeys, the real SIV proviral copy number may be around 10\% higher than indicated.

While the sample size of this present study is low and thus has limited statistical power, there was no strong trend between the SIV plasma viral load, the stage of SIV infection, or the CD4 cell count and the relative copy number distribution. For example, monkeys 8179 and 1740 differed more than $10^{4}$-fold in plasma virus titres but showed a similar provirus distribution in their splenocytes (Table 1). A similar observation was made previously when studying the HIV copy number distributions in splenocytes of 2 seropositive patients with Castleman disease [19]. Notably, in this latter study, the copy number distribution was higher with the majority of cells harbouring 3 to 4 proviruses. While the reason for this difference is unknown, it may well be related to the lymphoproliferative nature of the disease [25]. Nonetheless, with respect to recombination, any cell with a provirus copy number above 1 is able to generate virions with mixed RNA genomes that in the subsequent infection round will result in recombinant progeny.

How are infected splenocytes with multiple proviruses generated? The lack of a clear trend between the plasma viral load and the copy number distribution of this study and that of Jung et al. [19] suggest that cell-cell transmission events rather than circulating virus itself are the likely viral source. Indeed, infections by viruses deposited on Follicular Dendritic cells [26] or transferred from Dendritic cells to $\mathrm{T}$ cells in the process of antigen-specific stimulation [27] are highly efficient and may result in the transmission of multiple virions as demonstrated by more recent ex vivo studies [28,29].

The early onset of SIV multi-infection provides the fundamental mechanistic requirements for recombination to occur already at primary viremia. Indeed, when macaques were inoculated simultaneously with SIVmac239 $\Delta v p x$ or $\Delta v p r$ and SIVmac239 $\Delta n e f$, the emergence of wild-type virus was detected in blood in as little as 2 weeks postinoculation $[30,31]$. This was due to the large fitness advantage of the recombined wild-type over both deletion mutants. In naturally occurring HIV infections however, 


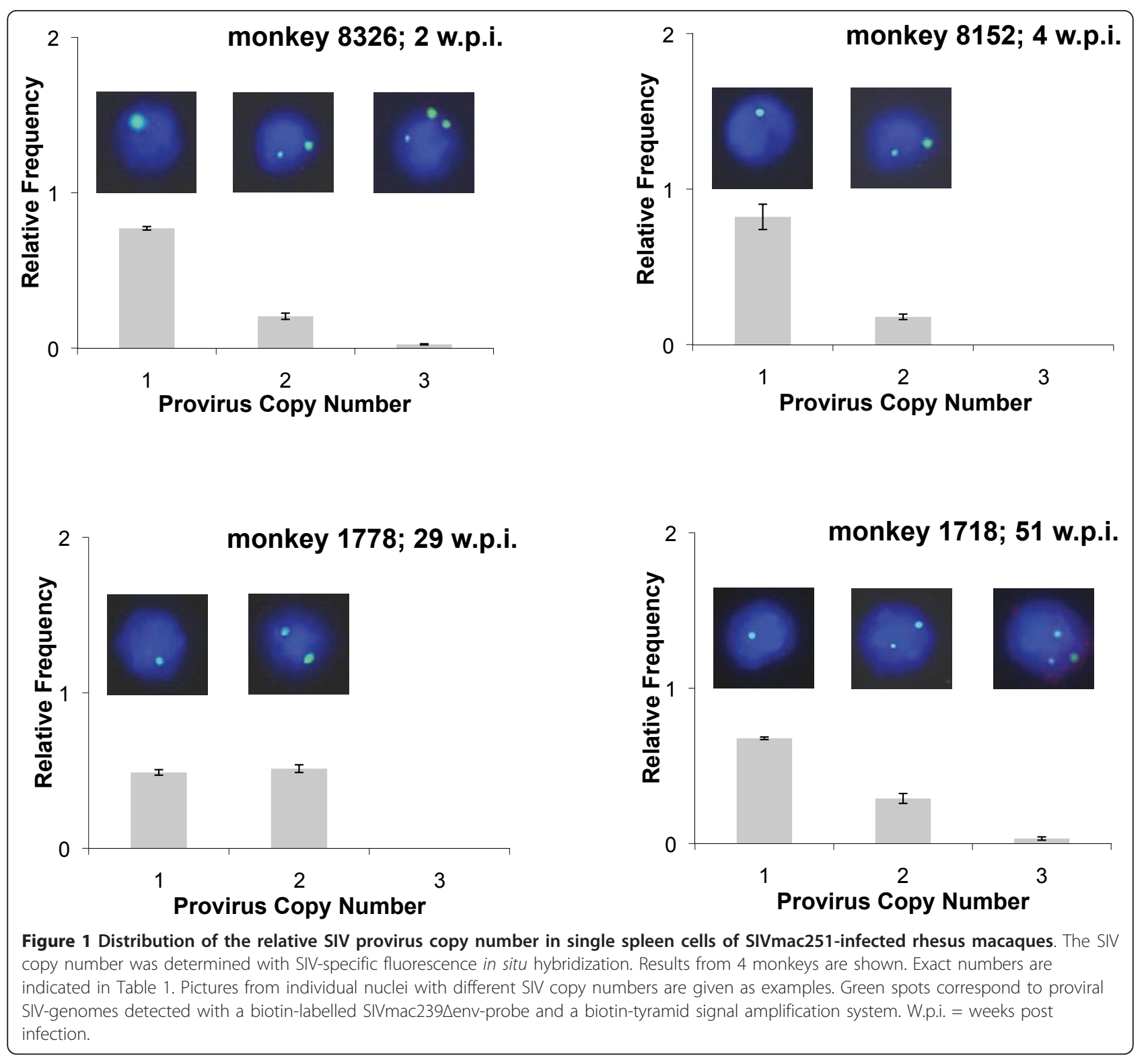

only one or very few virus variants are transmitted resulting in a rather homogenous virus population at primary viremia [32,33]. Consequently, any generated recombinant will remain unnoticed unless a fair degree of sequence diversity is generated over time by error prone replication rounds. This scenario is well documented and shows up in the time-structured sequence networks from HIV patients as well as clonal SIV infections of macaques [34-37].

\section{Conclusions}

In summary, SIV multi-infection of single cells within a lymphoid tissue is established during the primary infection phase and observed throughout the entire disease course. As a consequence, recombination events will inevitably occur and contribute to virus evolution.

\section{Methods}

Splenocytes were analyzed from 11 SIVmac251-infected monkeys that had been used in previously published infection studies [38]. Animals were housed at the German Primate Center under standard conditions and experiments were performed according to the German animal protection law which complies with the European Union guidelines on the use of non-human primates for biomedical research (approval 604.42502/08-02.95, Bezirksregierung Braunschweig). The animals had been 
Table 1 Characteristics of SIVmac251-infected rhesus macaques

\begin{tabular}{|c|c|c|c|c|c|c|c|}
\hline \multirow[t]{2}{*}{ Monkey } & \multirow[t]{2}{*}{$\begin{array}{l}\text { Duration of infection } \\
\text { (weeks) }\end{array}$} & \multirow[t]{2}{*}{$\begin{array}{l}\text { Absolute CD4+ T cells } \\
\text { (cell/ } / \mu \mathrm{l})\end{array}$} & \multirow[t]{2}{*}{$\begin{array}{c}\text { Plasma viral load (SIV- } \\
\text { RNA/ml) }\end{array}$} & \multirow[t]{2}{*}{$\begin{array}{l}\text { Number of infected cells } \\
\text { counted }\end{array}$} & \multicolumn{3}{|c|}{$\begin{array}{c}\text { Relative SIV copy } \\
\text { number distribution }\end{array}$} \\
\hline & & & & & $\begin{array}{c}1 \\
\text { copy }\end{array}$ & $\begin{array}{c}2 \\
\text { copies }\end{array}$ & $\begin{array}{c}3 \\
\text { copies }\end{array}$ \\
\hline $8310(I)$ & 0 & 804 & nd & - & - & - & - \\
\hline $8326(I)$ & 2 & 1980 & nd & 83 & 0.77 & 0.20 & 0.02 \\
\hline 7783 (C) & 2 & 471 & nd & 125 & 0.69 & 0.31 & - \\
\hline $8152(I)$ & 4 & nd & nd & 28 & 0.82 & 0.18 & - \\
\hline $7793(C)$ & 7 & 471 & nd & 122 & 0.80 & 0.20 & - \\
\hline $8179(\mathrm{C})$ & 12 & 252 & $7.7 \times 10^{3}$ & 52 & 0.73 & 0.27 & - \\
\hline $\begin{array}{c}1740(\mathrm{l}, \\
\mathrm{A})\end{array}$ & 13 & 131 & $2.3 \times 10^{8}$ & 77 & 0.73 & 0.27 & - \\
\hline 7785 (C) & 17 & 910 & nd & 45 & 0.67 & 0.33 & - \\
\hline 8159 (I) & 18 & 545 & nd & 163 & 0.72 & 0.28 & - \\
\hline $7786(C)$ & 19 & 840 & nd & 111 & 0.73 & 0.27 & - \\
\hline $\begin{array}{l}1778(1, \\
\text { A) }\end{array}$ & 29 & 571 & $3,1 \times 10^{6}$ & 41 & 0.49 & 0.51 & - \\
\hline $\begin{array}{l}\text { 1718, (I, } \\
\text { A) }\end{array}$ & 51 & 54 & $2.6 \times 10^{5}$ & 93 & 0.68 & 0.29 & 0.03 \\
\hline
\end{tabular}

Relative SIV copy number distribution including the number of infected cells counted and some characteristics of the SIV infection are given for all monkeys studied. The determined copy numbers are the result of 2 to 4 independent FISH experiments. The standard deviation of individual copy number counts was less than $10 \%$. Around 200 to 300 non-infected control cells were inspected in each FISH experiment. I = Rhesus macaques of Indian origin; $\mathrm{C}=$ Rhesus macaques of Chinese origin; $A=$ AIDS state.

infected intravenously with 100 MID $_{50}$ (monkey infectious dose infecting $50 \%$ of recipients) of a SIVmac251derived virus stock prepared in rhesus monkey peripheral blood mononuclear cells [39]. They were sacrificed at predetermined time points in the acute, post-acute, and early asymptomatic phase without clinical symptoms of immunodeficiency or euthanized due to early signs of AIDS. The eleven animals cover a time range from 2 weeks to 51 weeks post primary infection and a wide range of peripheral CD4 $\mathrm{T}$ cell counts (Table 1). The spleens were removed from anesthetized animals, cut into slices, and put into ice-cold Hank's balanced salt solution containing 3\% FCS. Spleen tissue was then forced through a $100 \mu \mathrm{m}$-mesh metal sieve with forceps. The dissociated material was left to settle for five minutes, and the single cell suspension in the supernatant was collected by centrifugation at $170 \mathrm{~g}$ for 10 minutes at $4^{\circ} \mathrm{C}$ and washed twice. Cells were counted in a Neubauer chamber and stored in liquid nitrogen. For the SIV-specific FISH, the thawed cells were stimulated for 2 days in the presence of $10 \mu \mathrm{M}$ AZT. The fixed cell nuclei were then hydridized with a biotin-labelled SIVmac239-specific DNA probe that was subsequently detected with a tyramide signal amplification (TSA) system. The fluorescence signals were analysed with an Olympus AX 70 epifluorescence microscope (Olympus Optical, Hamburg Germany). Pictures were documented with a digital camera Hamamatsu DC C4742-95 (Hamamatsu Photonics Deutschland GmbH, Herrsching am Ammersee, Germany) and an ISIS digital imaging analysis system
(Metasystems GmbH, Altlussheim Germany). A detailed description of the experimental procedures is given in the Additional file 1 and Additional file 2.

\section{Additional material}

Additional file 1: Detailed protocol for the preparation of cells for fluorescence in situ hybridization.

Additional file 2: Detailed protocol for the SIV-specific fluorescence in situ hybridization.

\section{Acknowledgements}

RS was supported by an EMBO Long Term Fellowship. AM was supported by grants from the Deutsche Forschungsgemeinschaft and the Spanish Ministry of Science and Innovation (SAF2010-21336).

\section{Author details}

'Department of Virology, Saarland University, Homburg D-66421, Germany. 2Department of Hematology and Oncology, Innsbruck Medical University, Innsbruck, Austria. ${ }^{3}$ Unit of Infection Models, German Primate Center, Göttingen D-37077, Germany. ${ }^{4}$ ICREA Infection Biology Laboratory, Department of Experimental and Health Sciences, University Pompeu Fabra, Barcelona 08003, Spain.

\section{Authors' contributions}

RS and AS performed the work. SS and US performed animal studies and collected the samples. RS and AM designed the study and wrote the paper. All authors read and approved the final manuscript.

\section{Competing interests}

The authors declare that they have no competing interests.

Received: 13 January 2012 Accepted: 23 April 2012

Published: 23 April 2012 


\section{References}

1. Roberts JD, Bebenek K, Kunkel TA: The accuracy of reverse transcriptase from HIV-1. Science 1988, 242:1171-1173.

2. Harris RS, Bishop KN, Sheehy AM, Craig HM, Petersen-Mahrt SK, Watt IN, Neuberger MS, Malim MH: DNA deamination mediates innate immunity to retroviral infection. Cell 2003, 113:803-809.

3. Lecossier D, Bouchonnet F, Clavel F, Hance AJ: Hypermutation of HIV-1 DNA in the absence of the Vif protein. Science 2003, 300:1112.

4. Mangeat B, Turelli P, Caron G, Friedli M, Perrin L, Trono D: Broad antiretroviral defence by human $A P O B E C 3 G$ through lethal editing of nascent reverse transcripts. Nature 2003, 424:99-103.

5. Mariani R, Chen D, Schrofelbauer B, Navarro F, Konig R, Bollman B, Munk C, Nymark-McMahon H, Landau NR: Species-specific exclusion of APOBEC3G from HIV-1 virions by Vif. Cell 2003, 114:21-31.

6. Zhang H, Yang B, Pomerantz RJ, Zhang C, Arunachalam SC, Gao L: The cytidine deaminase CEM15 induces hypermutation in newly synthesized HIV-1 DNA. Nature 2003, 424:94-98

7. Coffin JM: Structure, replication, and recombination of retrovirus genomes: some unifying hypotheses. J Gen Virol 1979, 42:1-26.

8. Cheynier R, Henrichwark S, Hadida F, Pelletier E, Oksenhendler E, Autran B, Wain-Hobson S: HIV and T cell expansion in splenic white pulps is accompanied by infiltration of HIV-specific cytotoxic T lymphocytes. Cell 1994, 78:373-387.

9. Coffin JM: Genetic diversity and evolution of retroviruses. Curr Top Microbiol Immunol 1992, 176:143-164.

10. Gratton S, Cheynier R, Dumaurier MJ, Oksenhendler E, Wain-Hobson S: Highly restricted spread of HIV-1 and multiply infected cells within splenic germinal centers. Proc Natl Acad Sci USA 2000, 97:14566-14571.

11. Meyerhans A, Cheynier R, Albert J, Seth M, Kwok S, Sninsky J, MorfeldtManson L, Asjo B, Wain-Hobson S: Temporal fluctuations in HIV quasispecies in vivo are not reflected by sequential HIV isolations. Cell 1989, 58:901-910.

12. Chen J, Powell D, Hu WS: High frequency of genetic recombination is a common feature of primate lentivirus replication. J Virol 2006, 80:9651-9658.

13. Jetzt $A E, Y u$ H, Klarmann GJ, Ron Y, Preston BD, Dougherty JP: High rate of recombination throughout the human immunodeficiency virus type 1 genome. J Virol 2000, 74:1234-1240.

14. Levy DN, Aldrovandi GM, Kutsch O, Shaw GM: Dynamics of HIV-1 recombination in its natural target cells. Proc Natl Acad Sci USA 2004, 101:4204-4209.

15. Onafuwa A, An W, Robson ND, Telesnitsky A: Human immunodeficiency virus type 1 genetic recombination is more frequent than that of Moloney murine leukemia virus despite similar template switching rates. J Virol 2003, 77:4577-4587.

16. Rhodes TD, Nikolaitchik O, Chen J, Powell D, Hu WS: Genetic recombination of human immunodeficiency virus type 1 in one round of viral replication: effects of genetic distance, target cells, accessory genes, and lack of high negative interference in crossover events. J Virol 2005, 79:1666-1677.

17. Mansky LM, Temin HM: Lower in vivo mutation rate of human immunodeficiency virus type 1 than that predicted from the fidelity of purified reverse transcriptase. J Virol 1995, 69:5087-5094.

18. Dang Q, Chen J, Unutmaz D, Coffin JM, Pathak VK, Powell D, KewalRamani VN, Maldarelli F, Hu WS: Nonrandom HIV-1 infection and double infection via direct and cell-mediated pathways. Proc Natl Acad Sci USA 2004, 101:632-637.

19. Jung A, Maier R, Vartanian JP, Bocharov G, Jung V, Fischer U, Meese E, Wain-Hobson S, Meyerhans A: Multiply infected spleen cells in HIV patients. Nature 2002, 418:144.

20. Chen J, Nikolaitchik O, Singh J, Wright A, Bencsics CE, Coffin JM, Ni N, Lockett S, Pathak VK, Hu WS: High efficiency of HIV-1 genomic RNA packaging and heterozygote formation revealed by single virion analysis. Proc Natl Acad Sci USA 2009, 106:13535-13540

21. Mayr L, Powell R, Kinge T, Nyambi PN: Sequence Analysis of the dimerization initiation site of concordant and discordant viral variants superinfecting HIV Type 1 patients. AIDS Res Hum Retroviruses 2011, 27:1231-1235.

22. Nikolaitchik OA, Galli A, Moore MD, Pathak VK, Hu WS: Multiple barriers to recombination between divergent HIV-1 variants revealed by a dualmarker recombination assay. J Mol Biol 2011, 407:521-531.
23. Sakuragi J, Sakuragi S, Ohishi M, Shioda T: Direct correlation between genome dimerization and recombination efficiency of HIV-1. Microbes Infect 2010, 12:1002-1011.

24. Naidu YM, Kestler HW, Li Y, Butler CV, Silva DP, Schmidt DK, Troup CD, Sehgal PK, Sonigo P, Daniel MD, et al: Characterization of infectious molecular clones of simian immunodeficiency virus (SIVmac) and human immunodeficiency virus type 2: persistent infection of rhesus monkeys with molecularly cloned SIVmac. J Virol 1988, 62:4691-4696.

25. Oksenhendler E, Duarte M, Soulier J, Cacoub P, Welker Y, Cadranel J, CazalsHatem D, Autran B, Clauvel JP, Raphael M: Multicentric Castleman's disease in HIV infection: a clinical and pathological study of 20 patients. AIDS 1996, 10:61-67.

26. Heath SL, Tew JG, Tew JG, Szakal AK, Burton GF: Follicular dendritic cells and human immunodeficiency virus infectivity. Nature 1995, 377:740-744.

27. Tsunetsugu-Yokota Y, Akagawa K, Kimoto H, Suzuki K, Iwasaki M, Yasuda S, Hausser G, Hultgren C, Meyerhans A, Takemori T: Monocyte-derived cultured dendritic cells are susceptible to human immunodeficiency virus infection and transmit virus to resting T cells in the process of nominal antigen presentation. J Virol 1995, 69:4544-4547.

28. Chen J, Dang Q, Unutmaz D, Pathak VK, Maldarelli F, Powell D, Hu WS: Mechanisms of nonrandom human immunodeficiency virus type 1 infection and double infection: preference in virus entry is important but is not the sole factor. J Virol 2005, 79:4140-4149.

29. Del Portillo A, Tripodi J, Najfeld V, Wodarz D, Levy DN, Chen BK: Multiploid inheritance of HIV-1 during cell-to-cell infection. J Virol 2011, 85:7169-7176.

30. Kim EY, Busch M, Abel K, Fritts L, Bustamante P, Stanton J, Lu D, Wu S, Glowczwskie J, Rourke T, et al: Retroviral recombination in vivo: viral replication patterns and genetic structure of simian immunodeficiency virus (SIV) populations in rhesus macaques after simultaneous or sequential intravaginal inoculation with SIVmac239Deltavpx/Deltavpr and SIVmac239Deltanef. J Virol 2005, 79:4886-4895.

31. Wooley DP, Smith RA, Czajak S, Desrosiers RC: Direct demonstration of retroviral recombination in a rhesus monkey. J Virol 1997, 71:9650-9653.

32. Herbeck JT, Rolland M, Liu Y, McLaughlin S, McNevin J, Zhao H, Wong K, Stoddard JN, Raugi D, Sorensen S, et al: Demographic processes affect HIV-1 evolution in primary infection before the onset of selective processes. J Virol 2011, 85:7523-7534.

33. Keele BF, Giorgi EE, Salazar-Gonzalez JF, Decker JM, Pham KT, Salazar MG, Sun C, Grayson T, Wang S, Li H, et al: Identification and characterization of transmitted and early founder virus envelopes in primary HIV-1 infection. Proc Natl Acad Sci USA 2008, 105:7552-7557.

34. Kils-Hutten L, Cheynier R, Wain-Hobson S, Meyerhans A: Phylogenetic reconstruction of intrapatient evolution of human immunodeficiency virus type 1: predominance of drift and purifying selection. J Gen Virol 2001, 82:1621-1627.

35. Pelletier E, Saurin W, Cheynier R, Letvin NL, Wain-Hobson S: The tempo and mode of SIV quasispecies development in vivo calls for massive viral replication and clearance. Virology 1995, 208:644-652.

36. Plikat U, Nieselt-Struwe K, Meyerhans A: Genetic drift can dominate shortterm human immunodeficiency virus type 1 nef quasispecies evolution in vivo. J Virol 1997, 71:4233-4240.

37. Wain-Hobson S, Renoux-Elbe C, Vartanian JP, Meyerhans A: Network analysis of human and simian immunodeficiency virus sequence sets reveals massive recombination resulting in shorter pathways. J Gen Virol 2003, 84:885-895.

38. Sopper S, Sauer U, Hemm S, Demuth M, Muller J, Stahl-Hennig C, Hunsmann G, ter Meulen V, Dorries R: Protective role of the virus-specific immune response for development of severe neurologic signs in simian immunodeficiency virus-infected macaques. J Virol 1998, 72:9940-9947.

39. Stahl-Hennig C, Voss G, Dittmer U, Coulibaly C, Petry H, Makoschey B, Cranage MP, Aubertin AM, Luke W, Hunsmann G: Protection of monkeys by a split vaccine against SIVmac depends upon biological properties of the challenge virus. AIDS 1993, 7:787-795

doi:10.1186/1742-4690-9-31

Cite this article as: Schultz et al: Stable multi-infection of splenocytes during SIV infection - the basis for continuous recombination. Retrovirology 2012 9:31. 